\title{
Comparison of Four Moisture Management Systems for Cutting Propagation of Bougainvillea, Hibiscus, and Kei Apple
}

\author{
K.W. Mudge \\ Department of Floriculture and Ornamental Horticulture, Cornell University, Ithaca, NY 14853 \\ V.N. Mwaja, ${ }^{2}$ F.M. Itulya, ${ }^{3}$ and J. Ochieng \\ Department of Horticulture, Egerton University, P. O. Box 536, Njoro, Kenya \\ Additional index words. cutting water relations, mist propagation, contact polyethylene, polyethylene tent, vapor density
deficit, Bougainvillea x Buttiana, Hibiscus rosa-sinensis, Dovyahs caffra
}

\begin{abstract}
The effects of four propagation moisture management systems on the water relations and rooting of cuttings of three tropical woody crops were investigated at a relatively cool, but high irradiance site. Leafy semihardwood or leafless hardwood cuttings of Bougainvillea x Buttiana Holtt. \& Standl. (bougainvillea), and leafy semihardwood cuttings of Hibiscus rosa-sinensis L. (hibiscus), and Dovyalis caffra (Hook. f. et Harv.) Warb. (kei apple) were propagated in shade under contact tent polyethylene enclosures or in the open with or without intermittent mist. Xylem water potential and leaf and air temperatures and relative humidity were monitored during the rooting period. Hardwood cuttings rooted better than softwood cuttings of bougainvillea. The best rooting of softwood cuttings of all three species was consistently associated with contact polyethylene, whereas open-propagated, nonmisted cuttings rooted poorly or not at all. The poor rooting of open-propagated nonmisted cuttings was associated with the most negative midday $\psi$ and the greatest water vapor density deficit of air surrounding the cuttings $\left(V_{D D}\right)$, but $\psi$ and VDD $_{A}$ were otherwise not consistently associated with success of rooting in other treatments. Midday $\psi$ of cuttings under contact polyethylene was either less negative or not different from that of other treatments despite the fact they exhibited the greatest daytime leaf and leaf to air temperature differences. Because ambient night temperatures were suboptimal for rooting, the warm air trapped beneath the polyethylene enclosures at night may have contributed to improved rooting in these treatments.
\end{abstract}

Cuttage is an extensively practiced and economical means of vegetative propagation for a wide range of woody plants cultivated for use as ornamental, fruit, or agroforestry crops. The development of intermittent mist systems and their widespread commercial availability in developed countries has greatly increased the range of species that can be propagated by cuttage. On the other hand, rural farmers, especially in developing countries, often do not have access to mist technology due to the expense or unavailability of the necessary hardware components and/or the lack of electricity and/or piped water supply. When automatic misting is not available, moisture management in cutting propagation is often the factor limiting success. Nonmist propagation systems involving passive moisture barriers in the form of polyethylene or glass enclosures have long been used to minimize moisture loss from cuttings. Recently, researchers at the Institute for Tropical Ecology have developed and characterized a nonmist propagation system appropriate for vegetative propagation of tropical woody plants when electricity and piped water are not available (Leakey et al., 1990; Newton and Jones, 1993a, 1993b).

The goal of successful moisture management in a cutting propagation facility is to minimize transpirational water loss while maximizing water uptake by cuttings. This can be achieved by maintaining high relative humidity $(\mathrm{RH})$ of the air surrounding the cuttings either by the use of mist or a moisture barrier like polyethylene, and by the use of shade and/or mist to avoiding high air temperature $\left(T_{A}\right)$ and high leaf to air temperature differences

Received for publication 15 June 1994. Accepted for publication 4 Oct. 1994. The cost of publishing this paper was defrayed in part by the payment of page charges Under postal regulations, this paper therefore must be hereby marked advertisement solely to indicate this fact.

${ }^{1}$ To whom repring requests should be addressed.

Currently with Monsanto Agricultural Group, Monsanto Co., St. Louis.

${ }^{3}$ Dean of the Faculty of Agriculture.
$\left(\mathrm{T}_{1-\mathrm{s}}\right)$. Loach $(1977,1988)$ and coworkers (Grange and Loach, 1983a, 1983 b), and Newton and Jones (1993b) have used cutting water potential $(\psi)$ as an indicator of the effects of environmental manipulations on the moisture status of cuttings.

Polyethylene moisture barriers are usually raised above the surface of the cuttings by at least several centimeters, by means of a wood or metal framework, to create a tent. A modification of raised polyethylene systems known as contact polyethylene (Loach, 1988) involves laying a thin sheet of polyethylene directly on top of, in direct contact with, the foliage of cuttings. Loach (1977) reported that cuttings frequently root better under contact polyethylene than in a polyethylene tent because $T_{L}, T_{A}$, and $T_{L-A}$ tend to be lower in the former.

In the western highlands of Kenya, where our research was conducted, cuttage is used to propagate a number of woody crops used for food (cassava), beverage (tea), as ornamentals (bougainvillea), or for agroforestry [Sesbania sesban (L.) Merrill]. Because small scale rural farmers do not have access to electricity, piped water, and/or mist system components, cuttings are frequently stuck in soil or a suitable rooting medium (sand), out in the open, under shade, where high VDDs prevail. Under such conditions only relatively easy-to-root species can be successfully rooted.

The objective of this research was to compare propagation success and cutting water stress for two low-tech nonmist cutting propagation systems - polyethylene tent and contact polyethylene -with the locally common practice of open propagation, and to compare the performance of all three low-tech systems to that of a relatively high-tech mist propagation system.

\section{Materials and Methods}

The species used in these experiments were Hibiscus rosasinensis L. (hibiscus), Bougainvillea x Buttiana 'Mrs. Butt' (bou- 
Table 1. Effect of four moisture management systems on the roots/rooted cutting (RRC) and percent rooting (\% R) of semihardwood and hardwood cuttings. In the case of bougainvillea, only a single block shade structure was used. For hibiscus and kei apple, treatment means within blocks are presented if there was a significant block effect or block $\times$ treatment interaction; otherwise treatment means pooled across blocks are presented.

\begin{tabular}{|c|c|c|c|c|c|c|c|}
\hline \multirow{2}{*}{$\begin{array}{l}\text { Species and } \\
\text { type of } \\
\text { cutting }\end{array}$} & \multirow{2}{*}{$\begin{array}{c}\text { Moisture } \\
\text { management } \\
\text { treatment }\end{array}$} & \multicolumn{2}{|c|}{ Block I } & \multicolumn{2}{|c|}{ Block II } & \multicolumn{2}{|c|}{$\begin{array}{l}\text { Pooled } \\
\text { blocks }\end{array}$} \\
\hline & & $\mathrm{RRC}$ & $\% \mathrm{R}$ & $\mathrm{RRC}$ & $\% \mathrm{R}$ & $\mathrm{RRC}$ & $\% \mathrm{R}$ \\
\hline \multicolumn{8}{|l|}{ Bougainvillea } \\
\hline \multirow[t]{4}{*}{ semihardwood } & Contact $^{2}$ & 2.8 & $32 a$ & $\cdots$ & --- & -- & -- \\
\hline & Tent & 4.5 & $24 \mathrm{a}$ & --- & --- & --- & --- \\
\hline & Mist & $\ldots$ & $0 \mathrm{~b}$ & --- & --- & --- & --- \\
\hline & Open & --- & $0 \mathrm{~b}$ & --- & --- & --- & -- \\
\hline$P($ ANOVA $)$ & Treatment & 0.4433 & 0.0001 & & & & \\
\hline \multirow[t]{4}{*}{ Bougainvillea hardwood } & Contact & 4.1 & $55 \mathrm{a}$ & -- & --- & -- & --- \\
\hline & Tent & 3.5 & $37 \mathrm{a}$ & --- & --- & --- & -- \\
\hline & Mist & 2.0 & $4 \mathrm{~b}$ & --- & --- & --- & --- \\
\hline & Open & 2.0 & $9 b$ & --- & --- & --- & \\
\hline$P($ ANOVA $)$ & Treatment & 0.1997 & 0.0002 & & & & \\
\hline \multirow[t]{4}{*}{ Hibiscus semihardwood } & Contact & $5.6 \mathrm{a}$ & --- & $9.8 \mathrm{a}$ & --- & --- & $64.5 \mathrm{a}$ \\
\hline & Tent & $4.7 \mathrm{ab}$ & --- & $4.7 \mathrm{~b}$ & $-\cdots$ & --- & $56.4 \mathrm{a}$ \\
\hline & Mist & $1.7 \mathrm{~b}$ & --- & $1.2 \mathrm{c}$ & --- & --- & $20.0 \mathrm{~b}$ \\
\hline & Open & $2.6 \mathrm{ab}$ & $\cdots$ & $0.2 \mathrm{c}$ & --- & -- & $8.2 \mathrm{~b}$ \\
\hline \multirow[t]{3}{*}{$P$ (ANOVA) } & Treatment & 0.0001 & 0.0001 & & & & \\
\hline & Block & 0.6508 & 0.9792 & & & & \\
\hline & $\mathrm{T} \times \mathrm{B}$ & 0.0269 & 0.2763 & & & & \\
\hline \multirow[t]{4}{*}{ Kei apple semihardwood } & Contact & $3.5 \mathrm{a}$ & --- & $4.6 \mathrm{a}$ & --- & --- & $58 \mathrm{a}$ \\
\hline & Tent & $4.1 \mathrm{a}$ & --- & $1.9 \mathrm{a}$ & --- & --- & $35 \mathrm{~b}$ \\
\hline & Mist & $3.1 \mathrm{a}$ & -- & $2.2 \mathrm{~b}$ & --- & --- & $36 \mathrm{~b}$ \\
\hline & Open & --- & --- & $1.0 \mathrm{~b}$ & $\cdots$ & -- & $1.0 \mathrm{c}$ \\
\hline \multirow[t]{3}{*}{$P$ (ANOVA) } & Treatment & 0.0247 & 0.0001 & & & & \\
\hline & Block & 0.1168 & 0.7719 & & & & \\
\hline & $\mathrm{T} \times \mathrm{B}$ & 0.0055 & 0.2974 & & & & \\
\hline
\end{tabular}

Letters differing within a column denote significant differences $(P=0.05)$, using Duncans multiple range test.

gainvillea), and Dovyalis caffra (kei apple). These were chosen because they are in high demand in Kenya for hedge and/or ornamental plantings. Bougainvillea and hibiscus, which are moderately difficult and easy to root, respectively, are commonly propagated in this region by sticking cuttings in the open under shade. Kei apple is typically propagated from seed, which is only available for a limited period each year and, even then, may not be available in sufficient quantities.

Experimental design. The experiments with hibiscus and kei apple were randomized complete-block designs with four moisture management treatments including contact polyethylene, polyethylene tent, mist, and open. Each species was treated as a separate experiment. For hibiscus and kei apple, two blocks in each experiment corresponded to two separate yet identical shade structures (described below), each containing all four treatments. In the case of bougainvillea, the experiment was not blocked (only one shade structure was used) because only a limited number of cuttings were available at a given time. The four moisture management treatments were each randomly assigned to one of the four propagation beds within each shade structure. For a given species (experiment), one wooden flat of cuttings consisting of five rows of eleven cuttings each, was placed in each of the moisture management treatments (beds) within a shade structure. The experiment was repeated at two times for hibiscus and bougainvillea, but only once for kei apple.

Propagation (shade) structures. Two identical, wood-framed, outdoor shade structures were built against the outside wall of a greenhouse at the Dept. of Horticulture, Egerton Univ., Njoro,
Kenya (elevation $2600 \mathrm{~m}$ ). Each shade structure was divided into four adjacent rectangular cutting propagation beds, $1 \mathrm{~m}$ wide $\mathrm{x} 2$ $\mathrm{m}$ long $\times 0.5 \mathrm{~m}$ high, corresponding to the four moisture management treatments (contact polyethylene, polyethylene tent, mist, and open). For shade, split bamboo poles $(\approx 5 \mathrm{~cm}$ in diameter) were placed horizontally, side by side, on a wooden frame, $1 \mathrm{~m}$ above ground level. Although the bamboo poles were in contact with each other, irregularities along their length created 1-to 3-mm gaps, through which narrow bands of direct sunlight passed to the otherwise shaded cutting beds. At midday on a typical cloudless day, irradiance (PAR), measured with a quantum sensor (LI190SB; Licor, Lincoln, Neb.) was $1811 \mu \mathrm{mol} \cdot \mathrm{m}^{-2} \cdot \mathrm{s}^{-1}$ in full sunlight outside the shade structure. Within the shade structure, irradiance was 91 and $1158 \mu \mathrm{mol} \cdot \mathrm{m}^{-2} \cdot \mathrm{s}^{-1}$ in full shade and sun gaps, respectively. Each of the four beds within each structure was filled to a depth of $15 \mathrm{~cm}$ with coarse gravel to facilitate drainage.

For the mist treatment, a l-cm-id. PVC pipe, plumbed to a tap (well) water source, was run lengthwise down the center of the bed, $80 \mathrm{~cm}$ above ground level ( $\approx 45 \mathrm{~cm}$ above the top of the cuttings). Two mist nozzles were located $1 \mathrm{~m}$ apart along the 2-m-long mist bed to supply uniform and complete mist coverage of the cuttings. To minimize fluctuations in $\mathrm{RH}$, polyethylene sheeting was placed around the four sides of each mist bed to a height of $80 \mathrm{~cm}$, but the top was left open. Mist was applied during daylight hours only. The system was controlled by a solenoid valve connected to an electronic interval timer that was set manually to mist for $6 \mathrm{sec}$ at intervals varying between 2 to $20 \mathrm{~min}$, depending upon prevailing irradiance and temperature conditions on a given day. 
For the polyethylene tent treatment, a frame of $\approx 1$.6-m-long $\times$ 2-cm-diameter cypress poles was arched across the 1-m-wide propagation bed perpendicular to its long axis and spaced $0.5 \mathrm{~m}$ apart. A single sheet of clear polyethylene, $0.025 \mathrm{~mm}$ thick (4 mil), was laid over the frame. The maximum height of the resulting hemicylindrical polyethylene tunnel was $\approx 0.5 \mathrm{~m}$ above ground level, and maximum headspace between the top of the cuttings (at the center of the arch) was $\approx 10 \mathrm{~cm}$. Edges of the polyethylene sheeting were secured tightly against the gravel floor of the propagation bed to maximize $\mathrm{RH}$.

For the contact polyethylene moisture management treatment, a sheet of polyethylene $0.006 \mathrm{~mm}$ (1 roil) thick x $80 \mathrm{~cm}$ x $60 \mathrm{~cm}$ was laid directly on top of a flat of cuttings and the edges were secured tightly to the outside of the wooden flat with a large circular rubber strip cut from a truck inner tube. In this treatment there was no headspace above the cuttings since the polyethylene sheet was in direct contact with the cuttings.

For the open moisture management treatment, an open flat of cuttings was placed in the remaining shaded bed within each shade structure.

Cutting preparation. Shoots up to 40 to $60 \mathrm{~cm}$ long were cut from current season's growth of either hibiscus or kei apple stock plants at the beginning of the day (between 0800 and $0930 \mathrm{HR}$ ), and placed immediately into wet burlap sacks to keep them cool and turgid until sticking was completed within the next 2 hours. Working in the shade, the terminal 8 to $12 \mathrm{~cm}$ of actively elongating (softwood) shoot tips was discarded and the remaining partially lignified shoots were divided into one to three $15-\mathrm{cm}$-long semihardwood cuttings, with the basal cut just below a node. In the case of bougainvillea, 80 -to 100 -cm shoots were cut from a single stock plant. These shoots consisted of current season's growth and a portion of the woody, previous season's growth. As for the other two species, semihardwood cuttings were taken from current season's growth, and hardwood cuttings were taken from the remaining lignified portion of previous season's growth. Leaves were stripped from the bottom $5 \mathrm{~cm}$ of semihardwood cuttings of all three species, and all leaves were stripped from bougainvillea hardwood cuttings. Cutting bases were dipped in water and then into a rooting hormone powder (Seradix 2) consisting of $0.8 \%$ IBA (1H-indole-3-butyric acid) in talc to a depth of $\approx 1 \mathrm{~cm}$. Excess rooting powder was tapped off before sticking. Cuttings were stuck to a depth of 5 to $6 \mathrm{~cm}$ in flats filled to a depth of $10 \mathrm{~cm}$ with prewetted coarse river sand. After sticking, cutting flats were watered before transferring one flat to each of the four cutting propagation beds within each shade structure. Polyethylene covers were removed once each week from the contact and tent polyethylene treatments so that the cuttings could be syringed with water, to the point of run through, and then aired for an additional $30 \mathrm{~min}$ before reclosure. Semihardwood cuttings assigned to the open treatment were syringed manually with water four times each day, except hardwood bougainvillea cuttings in the open treatment were syringed twice daily. The rooting period for bougainvillea, hibiscus, and kei apple cuttings was 90,79, and 70 days, respectively.

Cutting waterpotential. In a preliminary test, it was determined that the $\psi$ of single leaves removed from either hibiscus or bougainvillea cuttings was the same as whole-stem cuttings. Hence, for these two species, a single leaf was the unit of analysis for approximately weekly determinations of midday (1330 to 1500 $\mathrm{HR}) \psi$. Beginning at $1300 \mathrm{HR}$ of each sampling date for the experimental comparison of four moisture management systems, or at the various times throughout the day for the diurnal experiment, a single leaf was cut at the base of its petiole with a razor from each of five randomly selected cuttings per treatment. No more than one leaf was collected from any one cutting in a given flat during the course of an experiment. The severed leaf was immediately sealed in a plastic bag containing a $3 \times 5-\mathrm{cm}$ piece of moist paper toweling and placed in an insulated cooler to minimize changes in water potential during the interval between sampling and measurement (Allen et al., 1980). Leaf $\psi$ was determined with a Scholander pressure bomb (model 3005; Soil Moisture, Santa Barbara, Calif.). In the case of kei apple, single leaves were not suitable for determination of $\psi$ because air bubbles frequently made accurate determination of the endpoint impossible. For this species, an entire shoot cutting was used in the pressure bomb for measurement of $\psi$. Petiole or stem bases were not recut before insertion in the pressure bomb.

To gain an understanding of diurnal variation in $\psi$ of cuttings compared to intact stock plants, an experiment was conducted with bougainvillea cuttings propagated under mist. On 3 days during the course of a week, on days 1, 4, and 7, leafy semihardwood cuttings was harvested and stuck under the mist system as described above. The last group of cuttings were harvested and stuck by $1000 \mathrm{HR}$ on the seventh day, and, on the same day, leaf samples were harvested for determination of $\psi$ from all three groups of cuttings (1-, 4-, and 7-day-old) and from the stock plant, at the times indicated in Table 2.

Temperature and $R H$ Several times during the course of each experiment, $\mathrm{T}_{\mathrm{L}}$ and $\mathrm{T}_{\mathrm{A}}$ measurements were taken simultaneously for each of the four treatments within one of the shade structures. Copper constantan thermocouples (Omega, Stamford, Corm.), were connected to an 8-channel datalogger (model 21X; Campbell Scientific, Logan, Utah) programmed to acquire temperature data every 10 min. For $T_{L}$ measurement, the tip of a thermocouple was placed in contact with the lower leaf surface of a representative cutting near the center of the propagation flat, and for measurement of $\mathrm{T}_{\mathrm{A}}$, another thermocouple was placed 5 to $10 \mathrm{~mm}$ below the lower surface of the same leaf. $\mathrm{T}_{\mathrm{L}}$ and $\mathrm{T}_{\mathrm{A}}$ measurements were collected continuously for 48 to $72 \mathrm{~h}$, replicated on at least two separate occasions. RH was determined by placing an RH/temperature sensor (model 207; Campbell Scientific) within the canopy of a flat of cuttings. $\mathrm{RH}$ and associated $\mathrm{T}_{\mathrm{A}}$ measurement was replicated simultaneously with three separate sensors within a single moisture management treatment (flat). Due to the limited number of datalogger channels, RH of all four moisture management treatments could not be monitored simultaneously. Instead all three $\mathrm{RH} /$ temperature sensors were placed within a single treatment flat and then moved to each of the remaining three treatment flats for $24 \mathrm{~h}$ at each location. Hence the four treatments were sampled sequentially rather than simultaneously. Data presented are from a series of 4 consecutive days selected for greatest uniformity with respect to ambient irradiance (cloudless days),

Table 2. Effect of time of day and age of cutting on $\psi$ (MPa) of bougainvillea semihardwood cuttings under mist.

\begin{tabular}{|c|c|c|c|c|}
\hline \multirow[b]{2}{*}{$\begin{array}{l}\text { Sampling } \\
\text { time (HR) }\end{array}$} & \multicolumn{3}{|c|}{ Age of cuttings } & \multirow{2}{*}{$\begin{array}{c}\text { Stock } \\
\text { plant } \\
\text { (mean } \pm \text { SD) }\end{array}$} \\
\hline & $\begin{array}{c}1 \text { Day } \\
\text { (mean } \pm \mathrm{SD})\end{array}$ & $\begin{array}{c}4 \text { Days } \\
\text { (mean } \pm S D)\end{array}$ & $\begin{array}{c}7 \text { Days } \\
\text { (mean } \pm \text { SD) }\end{array}$ & \\
\hline 0500 & --- & $-0.4 \pm 0.1$ & $-0.4 \pm 0.1$ & $-0.4 \pm 0.1$ \\
\hline 0700 & --- & $-0.4 \pm 0.7$ & $-0.4 \pm 0.0$ & $-0.4 \pm 0.1$ \\
\hline 1000 & $-0.6 \pm 0.2$ & $-0.7 \pm 0.2$ & $-0.7 \pm 0.4$ & $-0.6 \pm 0.1$ \\
\hline 1200 & $-0.7 \pm 0.2$ & $-1.0 \pm 0.2$ & $-0.9 \pm 0.4$ & $-0.7 \pm 0.1$ \\
\hline 1400 & $-0.8 \pm 0.4$ & $-1.3 \pm 0.3$ & $-1.8 \pm 0.2$ & $-1.2 \pm 0.1$ \\
\hline 1600 & $-0.8 \pm 0.3$ & $-1.2 \pm 0.4$ & . $-1.6 \pm 0.3$ & $-1.0 \pm 0.1$ \\
\hline
\end{tabular}




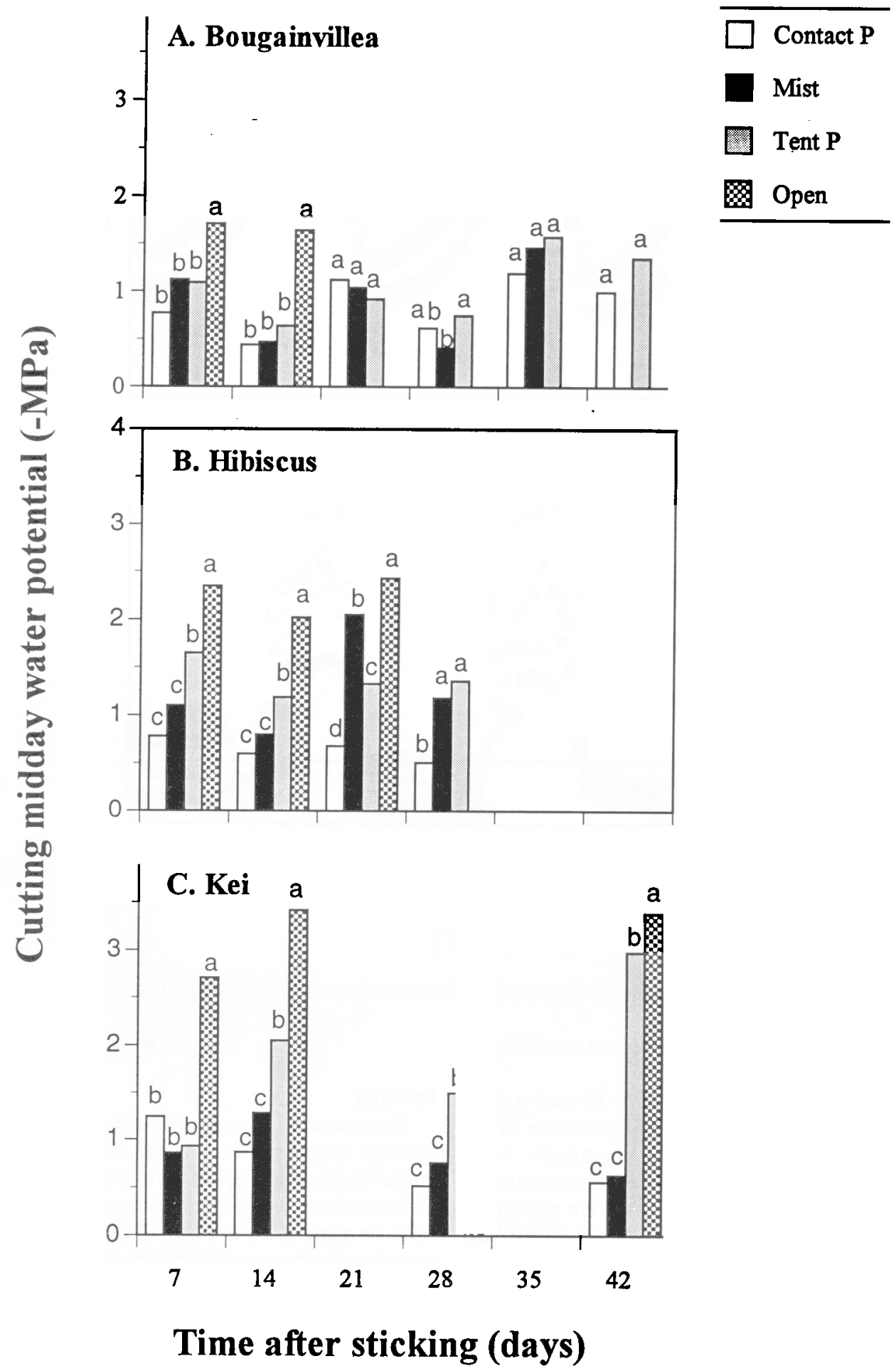

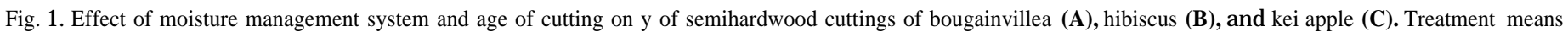
associated with different letters within a group of moisture management treatments for a given day denote significant differences at $P=0.05$.

temperature, and $\mathrm{RH}$. $\mathrm{VDD}_{\mathrm{L}-\mathrm{A}}$, as a direct measure of the driving force for water loss from cuttings, could not be calculated from the data collected during this study because concurrent measurement of $T_{L}, T_{A}$, and $\mathrm{RH}$ could not be made simultaneously due to the limited number of data logger channels and sensors available. Alternatively, the air vapor density deficit $\left(\mathrm{VDD}_{\mathrm{A}}\right)$ was calculated from the $\mathrm{RH} /$ temperature sensor output, as the difference between saturated vapor density and actual vapor density (from $\mathrm{RH}$ ) at a given temperature, as described by Campbell (1977). VDD is an indication of the evaporative potential of the air and, hence, is a similar but more conservative estimate of potential transpiration than $\mathrm{VDD}_{\mathrm{L}-\mathrm{A}}$ (the two are identical when $\mathrm{T}_{\mathrm{L}-\mathrm{A}}=0$ ).

Evaluation of rooting. Cuttings were evaluated for percentage rooting $(\% \mathrm{R})$ and number of roots per rooted cutting (RRC) within each row, when it was determined that the best treatment for a given species had achieved a commercially 


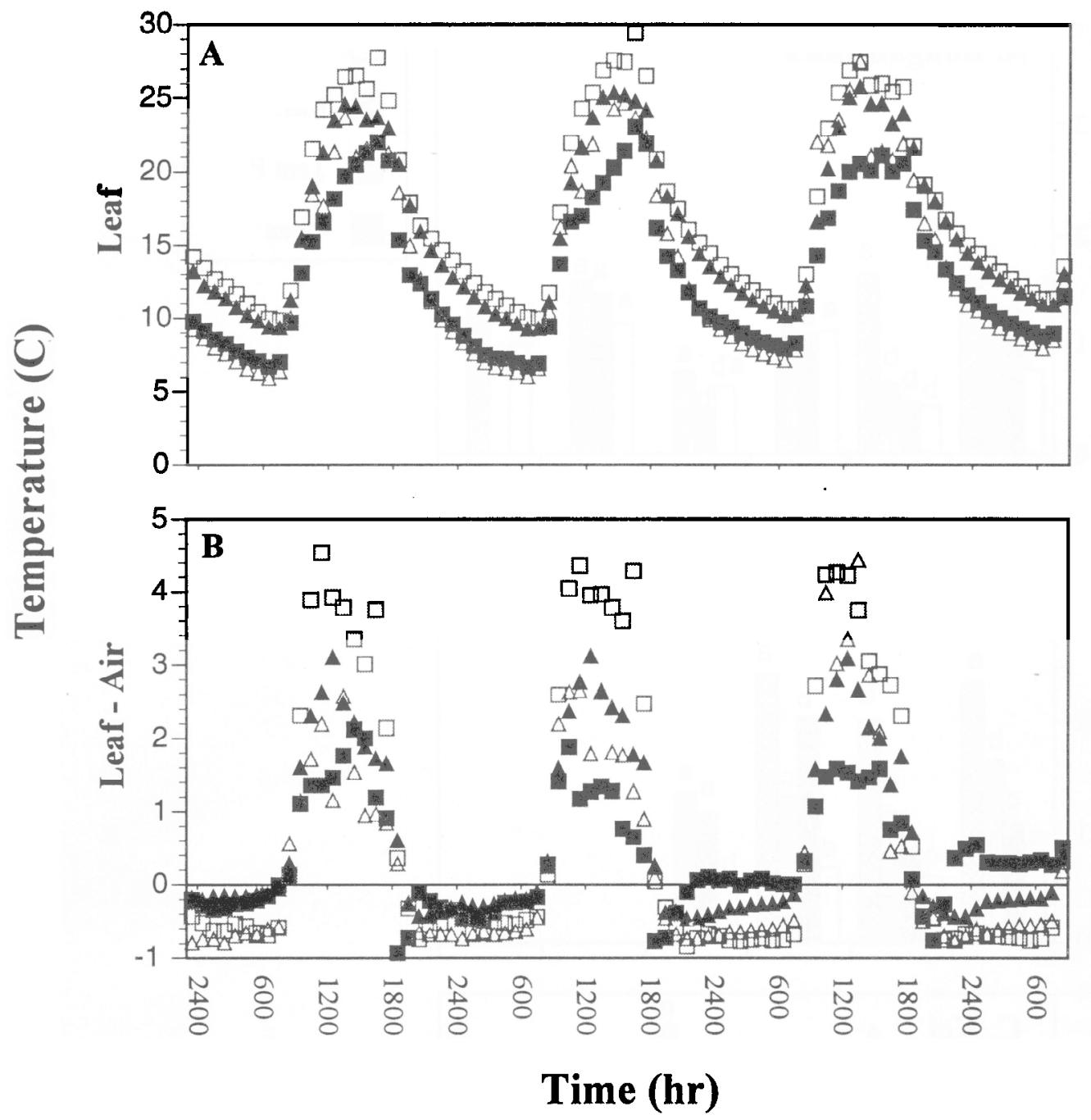

Fig. 2. Effect of moisture management system on leaf (A) and Leaf-air temperature differences (B) for leafy semihardwood hibiscus cuttings during a typical 3-day period.

acceptable (survivable) level of root development on cuttings that had rooted.

Statistical analysis. Rooting data (RRC and \% R) and $\psi$ data were subjected to ANOVA using SAS's GLM procedure (SAS Institute, Cary, N.C.). Moisture management treatments were treated as class variables. Percent rooting data were arcsin-transformed for analysis, but untransformed $\% \mathrm{R}$ values are presented in Table 1. RRC for an unrooted cutting was treated as missing data rather than zero. When block or block $\mathrm{x}$ treatment $(\mathrm{B} \times \mathrm{T})$ interactions were not significantly different at $P=0.05$, data from both blocks were pooled to give overall treatment means on which Duncan's multiple range test was performed. When a block (shade structure) effect, or when a B x T interaction was significant, treatment means for each block are presented separately in Table 1 , and Duncan's multiple range test applied to each block independently. Water potential data were subjected to ANOVA with pooled means used for Duncan's means separation test if B or B x $T$ was not significant and independently if either was significant. Waterpotential data for each sampling date (approximately weekly) were analyzed separately because ambient environmental conditions (temperature, irradiance, $\mathrm{RH}$ ) varied. Hence, no attempt was made to statistically compare $\psi$ measurements between sampling dates. In the case of bougainvillea, hardwood and semihardwood cuttings were treated as separate experiments with respect to statistical analysis.

\section{Results}

\section{Rooting}

Bougainvillea. Rooting of polyethylene-enclosed semihardwood cuttings ranged between $24 \%$ in the polyethylene tent to $32 \%$. for contact polyethylene, but the difference was not significant (Table 1). Unenclosed bougainvillea semihardwood cuttings, either in the open or misted, did not root. The $\% \mathrm{R}$ of hardwood cuttings that rooted under the two polyethylene enclosures was $37 \%$ to $55 \%$. for the tent and the contact polyethylene treatments, respectively. The difference was not significant. Hardwood cuttings rooted $<10 \%$ in either unenclosed treatment (mist or open). Although not significantly different from each other, mist and open-treated cuttings rooted significantly less cuttings in either of the polyethyleneenclosed moisture management treatments. There were no differences in RRC among the four treatments. Although the hardwood cuttings were defoliated at the start of the experiment, shoot development from remaining nodal buds resulted in the defoliation of about the same percentage of cuttings as rooted, but there was not a one-to-one correspondence between rooting and defoliation (data not shown).

Hibiscus. The rooting period for hibiscus cuttings was 79 days. Because there was no significant effect of shade structure (block) on $\% \mathrm{R}$, the means presented in Table 1 are pooled across blocks. The percentage of leafy semihardwood hibiscus cuttings that 


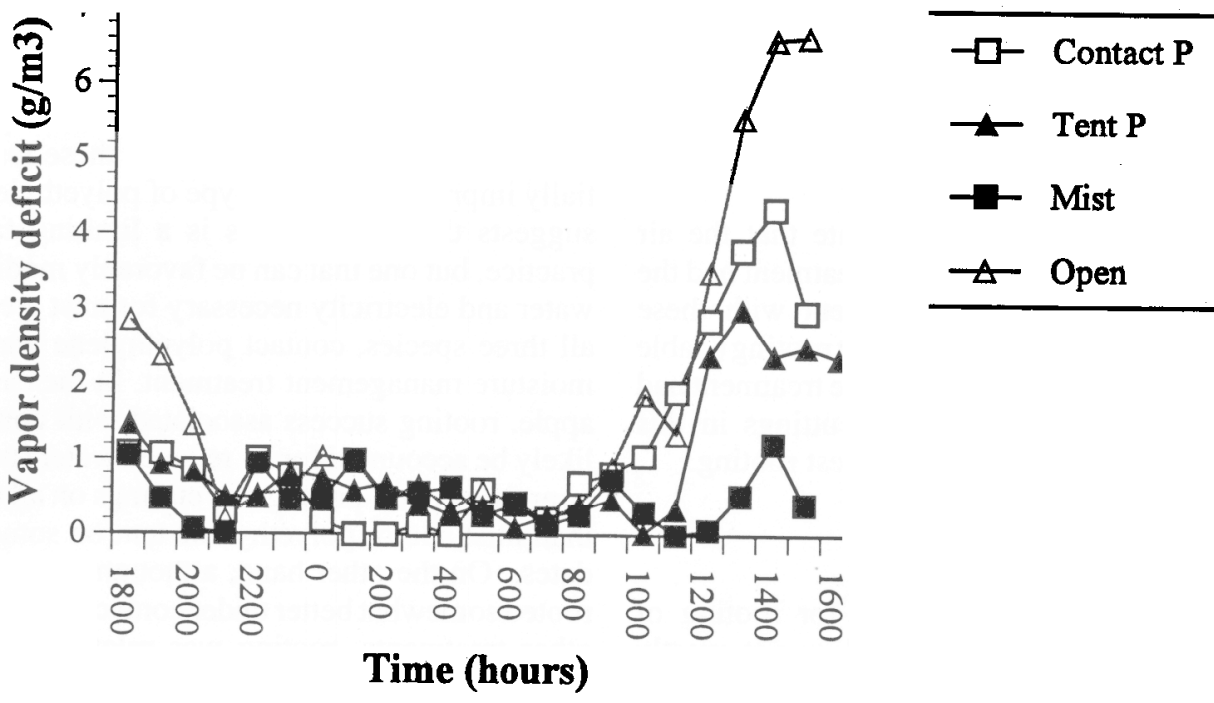

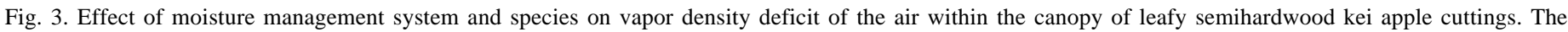
four moisture management systems were sampled on 4 conservative similar days.

rooted under either the contact or tent polyethylene enclosures was significantly higher than for misted or nonmisted unenclosed cuttings, but there was no significant difference between either polyethylene enclosure or between either unenclosed treatment. For RRC, separate block means are presented in Table 1 since there was a significant difference between shade structures (blocks). Within either of the blocks, the contact polyethylene treatment was the most effective.

Kei apple. There was no significant effect of shade structure (block) on \% R (Table 1). Fifty-eight percent of semihardwood kei apple cuttings rooted under contact polyethylene, which was significantly greater than the other three treatments. Polyethylene tent enclosed cuttings and misted cuttings rooted $\approx 35 \%$, whereas $<1 \%$ of the nonmisted open-propagated cuttings rooted. For RRC, there was a significant block $\mathrm{x}$ treatment interaction such that the polyethylene enclosed cuttings had significantly more RRC than misted cuttings in one shade structure (block II), whereas all three treatments which rooted had equivalent RRC in the other shade structure.

\section{Cutting water relations}

Bougainvillea. The $\psi$ was measured only for leafy semihardwood cuttings of this species because a reliable end point could not be determined from the shoot base of leafless hardwood cuttings because of air bubbles.

Diurnal variation in $\psi$ of 1,4 , and 7-day-old bougainvillea cuttings propagated under mist compared to intact stock plants is shown in Table 2. Environmental conditions prevailing in the mist system (foliar irrigation, shading, and the reduction in $T_{L}$ and $T_{A}$ accruing from both) prevented the development of water potentials any lower than the those of the intact stock plant for the first 4 days after sticking. Seven-day-old cuttings, however, developed $\psi$ substantially lower than the stock plant. Overnight recovery from daytime moisture deficits was apparent from the low predawn $\psi$. Rooting was not determined for cuttings in this experiment.

In the subsequent experimental comparison of the four moisture management systems, the lowest $\psi(-1.75 \mathrm{MPa})$ for bougainvillea cuttings occurred during the first 2 weeks in the nonmisted open treatment (Fig. 1A), and by the third week these cuttings in this treatment were completely defoliated so that no further $\psi$ measurements could be made and no cuttings rooted (Table 1).
Although cuttings under mist also failed to root, $\psi$ was not significantly lower than those under contact polyethylene or the polyethylene tent, which rooted $32 \%$ and $24 \%$, respectively. However, by the sixth week, misted cuttings had defoliated and no further $\psi$ data could be taken. Bougainvillea cuttings defoliated and died at relatively higher $\psi$ compared to hibiscus and kei apple. Hence, for bougainvillea, higher $\psi$ tended to be associated with rooting success.

Hibiscus. Cuttings in either the contact polyethylene or tent treatments, which each rooted $>50 \%$ (Table 1), did not develop xylem water potentials lower than $-1.6 \mathrm{MPa}$ at any time during the experiment (Fig. 1B), and $\psi$ of the former was consistently higher than the latter. In fact, $\psi$ of cuttings under contact polyethylene was consistently higher than that of the stock plant, which ranged from -0.71 to $-0.87 \mathrm{MPa}$ during the course of the experiment (data not shown). Misted cuttings, which rooted only $20 \%$, exhibited more variation in $\psi$ over time than the other treatments. During the first 2 weeks $\psi$ of misted cuttings was significantly higher than that of cuttings in the polyethylene tent for the first 2 weeks. By the third week $\psi$ of misted cuttings was significantly lower than that of cuttings in either polyethylene-enclosed treatment, but by the fourth week there was no difference between misted cuttings and those in the polyethylene tent. Nonmisted, open-propagated cuttings, which rooted least of all treatments $(<10 \%)$, exhibited consistently lower $\psi$ than any other treatment. B y the fourth week, all cuttings in this treatment had defoliated and no further $\psi$ measurements could be taken. Overall, $\psi$ was more predictive of rooting success of hibiscus cuttings than it was for bougainvillea.

Kei apple. Although kei apple cuttings, like those of bougainvillea and hibiscus, propagated under contact polyethylene, rooted better than other treatments (Table 1), $\psi$ was equal to orhigherthan cuttings under mist (Fig. 1C). Surprisingly, cuttings propagated in the polyethylene tent had significantly lower $\psi$ than those under mist, especially at the sixth week, although rooting of these two treatments was not significantly different (Table 1). Not surprisingly, nonmisted, open-propagated cuttings which rooted very poorly, had significantly lower $\psi$ than any other treatment.

Temperature and $R H$. Representative simultaneous $\mathrm{T}_{\mathrm{L}}$ and $\mathrm{T}_{\mathrm{L}-\mathrm{A}}$ data for hibiscus cuttings over a typical interval (cloudless conditions) are shown in Fig. 2A and B. Temperature trends were similar for bougainvillea and kei apple. Contrary to expectation, 
the greatest $\mathrm{T}_{\mathrm{L}}$ (Fig. 2A) and $\mathrm{T}_{\mathrm{L}-\mathrm{A}}$ (Fig. 2B) occurred in the contact polyethylene treatment, despite the fact that this treatment had the highest $\psi$ overall (Fig. 1B) and also the best rooting (Table 1). Mist dramatically reduced $\mathrm{T}_{\mathrm{L}}$ and $\mathrm{T}_{\mathrm{L}-\mathrm{A}}$, despite the poor performance of this treatment with respect to rooting of hibiscus cuttings (Table 1).

The $\operatorname{VDD}_{\mathrm{A}}$ values presented in Fig. 3 indicate that the air surrounding the cuttings in the open, nonmisted treatment had the greatest evaporative potential, which is consistent with these cuttings having the lowest $\psi$ (Fig. 1) and the poorest rooting (Table 1). Surprisingly, air within the contact polyethylene treatment had the next greatest $\mathrm{VDD}_{\mathrm{A}}$, despite the fact that cuttings in this treatment exhibited the least negative $\psi$ and the best rooting.

\section{Discussion}

To maintain cell turgor, which is essential for rooting of cuttings, it is critical that transpirational water loss not greatly exceed uptake for a prolonged period. Assuming the moisture content of a rooting medium is not limiting, the balance between water uptake and loss from cuttings is mediated by the $\mathrm{VDD}_{\mathrm{L}-\mathrm{A}}$, between the leaf and the surrounding air, and by resistances to the flux of water within the system, including resistance between the cutting base and the rooting medium, resistance within the xylem of the cutting, and the resistance between leaves and the surrounding air (mainly stomatal resistance). By manipulating the cuttings environment, the propagator can take steps to minimize $\mathrm{VDD}_{\mathrm{L}-\mathrm{A}}$ and maximize uptake to maintain a favorable water balance. The most obvious approaches to minimizing $\mathrm{VDD}_{\mathrm{L}-\mathrm{A}}$ are to increase $\mathrm{RH}$ of the air, decrease $\mathrm{T}_{\mathrm{A}}$ and/or $\mathrm{T}_{\mathrm{L}-\mathrm{A}}$. These objectives are readily accomplished by use of intermittent mist (Hess and Snyder, 1955; Grange and Loach, 1983a), although RH tends to fluctuate with mist cycling. Nonmist propagation systems involving polyethylene barriers minimize $\mathrm{VDD}_{\mathrm{L}-\mathrm{A}}$ by increasing $\mathrm{RH}$ (without the short-term fluctuations associated with intermittent mist). However, enclosed systems easily overheat, necessitating shading to reduce ambient irradiance.

Using cutting $\psi$ as an indicator of cutting water stress, Loach (1977) pointed out that, under relatively warm, high irradiance conditions, cuttings propagated under mist tend to maintain higher $\psi$ (less internal water stress) and, consequently, root better than those under polyethylene barriers primarily because of the reduction in $\mathrm{VDD}_{\mathrm{L}-\mathrm{A}}$ associated with decreased $\mathrm{T}_{\mathrm{A}}$ and $\mathrm{T}_{\mathrm{L}-\mathrm{A}}$ under mist. On the other hand, under relatively cooler, lower irradiance ambient conditions, where overheating is less of a problem, cuttings propagated under a polyethylene barrier often maintain less negative $\psi$ and ultimately root better than those under mist because $\mathrm{RH}$ under polyethylene is higher and fluctuates less than under mist. Recently, Newton and Jones (1993a) compared the microclimate of mist and nonmist (polyethylene enclosed) systems, and, in contrast to the findings of Loach (1977), they reported that $T_{L}, T_{A}$, and $T_{L-A}$ were greater and consequently VPD was greater under mist than nonmist, although there was no significant difference in rooting (Newton and Jones, 1993b).

The importance of water stress as a limiting factor in the rooting of cuttings propagated under the conditions of this study was initially suggested by the decline in $\psi$ of bougainvillea cuttings over the course of the first 7 days under mist (Table 2). This was unexpected since the mist environment is often regarded as approaching optimal water relations, especially under high irradiance (Loach, 1977) like that prevailing at the equatorial site where these experiments were performed. At the other extreme, an open nonmisted treatment was included in the comparison of moisture management treatments to approximate the locally common practice of rooting cuttings (including hibiscus and bougainvillea) under shade. The finding that open-propagated cuttings of all three species consistently exhibited the poorest rooting (Table 1) and the most negative $\psi$ (Fig. 1), and that these responses were substantially improved by either type of polyethylene enclosure strongly suggests that water stress is a limiting factor in conventional practice, but one that can be favorably modified, even if the piped water and electricity necessary for mist are not available. Across all three species, contact polyethylene was the most successful moisture management treatment. In the case of hibiscus and kei apple, rooting success associated with contact polyethylene can likely be accounted for by reduced water stress, i.e., higher $\psi$ than nonmisted open-propagated cuttings on all occasions and lower $\psi$ than mist and/or polyethylene tent on some but not all sampling dates. On the other hand, although leafy bougainvillea cuttings rooted somewhat better under contact polyethylene $(32 \%)$ than the other treatments, rooting was relatively low in all treatments. These considerations along with the decline in $\psi$ over the first 7 days under mist (Table 2), and the general lack of significant differences in $\psi$ for the different treatments (Fig. 1) suggests that water stress may have been limiting in bougainvillea cuttings, regardless of moisture management treatment. Similar declines in cutting $\psi$ and in xylem conductance overtime have been noted by Ikeda and Suzaki (1986) and by Grange and Loach (1983b). Scanning electron microscope evidence presented by Ikeda and Suzaki (1986) suggested that increasing resistance (decreasing conductance) to water flow within the xylem was due to gradual occlusion of xylem elements at the base of the cutting with tyloses (Populus sp.) or aspirated pits (Cryptomeria sp.). Loach (1988) suggested that xylem cavitation may be the primary cause of reduced hydraulic conductance in some species.

In addition to the effects of the four moisture management treatments used in this study on cutting water relations and ultimately on rooting, treatment effects on temperatures within the leaf and air components of the systems were evaluated as well. These were considered relevant, not only because of temperature effects on the driving force for water loss from cuttings $\left(\mathrm{VDD}_{\mathrm{L}-\mathrm{A}}\right)$, but also because of the effect of temperature on the rate of other physiological and metabolic processes involved in rooting (respiration rates, enzyme activities). $T_{L}$ and $T_{L-A}$ and the $V_{D D}$ measurements presented in Figure 3 are consistent with earlier observations by Hess and Snyder (1955) and by Grange and Loach (1983a) that misting reduces $T_{\mathrm{L}-\mathrm{A}}$ and, hence, reduces $\mathrm{VDD}_{\mathrm{L}-\mathrm{A}}$, compared to polyethylene enclosed, nonmisted cuttings. Newton and Jones (1993a), however, reported the opposite trend, i.e., temperatures were higher under mist than in a polyethylene tent. This is perplexing, especially in light of their report that cutting $\psi$ was higher under mist than polyethylene (Newton and Jones, 1993 b). Their suggestion that the duration or frequency of mist in their experiment could have been suboptimal may account for their atypical temperature profile.

As in our study, Loach ( 1977) reported that cuttings rooted better under contact polyethylene than a tent. He reported that $\mathrm{T}_{\mathrm{L}-\mathrm{A}}$ and consequently $\mathrm{VDD}_{\mathrm{L}-\mathrm{A}}$ were lower in the former, which he attributed to greater heat loss from the contact system due to the thinner (less insulating) polyethylene sheet used. He also suggested that the thin film of water, which inevitably condenses between the leaf and the contact polyethylene sheet (leaves are not in contact with the sheet in T), facilitates heat transfer from the system. Although the end result was similar in our study, i.e., cuttings under contact polyethylene rooted as well as or better and had higher $\psi$ than those under the polyethylene tent in all three species, nonetheless, $\mathrm{T}_{\mathrm{L}}$ and $\mathrm{T}_{\mathrm{L}-\mathrm{A}}$ were 
2 or more degrees warmer in the contact polyethylene system. Better rooting and higher $\psi$ is particularly surprising considering that the evaporative potential of the air $\left(\mathrm{VDD}_{\mathrm{A}}\right)$ surrounding cuttings in the contact polyethylene treatment was actually greater than for misted cuttings or those under the polyethylene tent. This suggests that stomata on leaves of cuttings under contact polyethylene may have closed sooner than those in the other treatments (especially open nonmisted cuttings). Earlier stomatal closure may have occurred in response to the higher temperatures and/or earlier water deficits, which in turn reduced further water loss from contact polyethylene enclosed cuttings. Continued stomatal closure coupled with water uptake from the rooting medium may have restored $\psi$ to a relatively higher value in cuttings under contact polyethylene than in other treatments.

Regardless of its cause, the relatively higher $\psi$ associated with contact polyethylene cuttings probably contributed to superior rooting in this treatment. Nevertheless, warmer night temperatures, independent of any effect on $\psi$, probably contributed as well. Nightly minimum leaf temperatures were as low as 6 to $8 \mathrm{C}$ in the unenclosed misted and nonmisted (open) systems, but they were $\approx 2$ to 3 degrees warmer in the contact and tent polyethylene enclosed systems. The low night temperatures prevailing in the Njoro area of Kenya, where this study was conducted, are suboptimal for rooting (Carpenter, 1989), hence, the warm air trapped within the polyethylene enclosures may have contributed to the improved rooting associated with these two treatments. In the case of Kei apple, elevated night temperatures associated with the enclosed polyethylene treatments compared to the unenclosed treatments may account for the fact that tent-enclosed cuttings rooted better than misted cuttings despite the lower $\psi$ of the former, from day 14, onward.

Overall, these experiments reinforce Loach's view (1988) that, although mist may be the propagation technology of choice when relatively high temperature, high irradiance conditions prevail, well-managed enclosed nonmist systems may be superior when irradiance and/or temperature levels are relatively low. Even though day $\mathrm{T}_{\mathrm{A}}$ and $\mathrm{T}_{\mathrm{L}}$ in the polyethylene-enclosed treatments were relatively high in the present study, the elevation of the low ambient night temperatures within the polyethylene barriers seemed to have had an overriding influence. The principal finding of this study-that propagation of cuttings under polyethylene enclo- sures resulted in more favorable water relations and better rooting than either the simpler alternative of open propagation or the technically more involved use of mist-gives practitioners of lowinput sustainable woody plant production a practical tool with which to increase production. Furthermore, the finding that contact polyethylene-enclosed cuttings rooted at least as well as those within the tent, in the case of hibiscus or bougainvillea and better in the case of kei apple, is encouraging, since the former is the least expensive and the most easily implemented of the moisture management systems investigated in this study.

\section{Literature Cited}

Allen, J. J., T.A. Nell, J.A. Joiner, and L.G. Albrigo. 1980. Effects of leaf position and storage conditions on pressure bomb measurement of leaf water potential in chrysanthemums. HortScience 15:808-809.

Campbell, G.S. 1977. An introduction to environmental biophysics. Springer-Verlag, New York.

Carpenter, W.J. 1989. Medium temperature influences the rooting response of Hibiscus rosa-sinensis L. J. Environ. Hort. 7:143-146.

Grange, R. I., and K. Loach. 1983a. Environmental factors affecting water loss from leafy cuttings in different propagation systems. J. Hort. Sci. 58:1-7.

Grange, R.I. and K. Loach. 1983b. The water economy of unrooted leafy cuttings. J. Hort. Sci. 58:9-17.

Hess, C.E. and W. E. Snyder. 1955. A physiological comparison of the use of mist with other propagation procedures used in rooting cuttings. Proc. 14th Hort. Congress, The Hague, Netherlands. 2:11 33-1 139.

Ikeda, T. and T. Suzaki. 1986. Influence of hydraulic conductance of xylem on water status in cuttings. Can. J. For. Res. 16:98-102

Leakey, R.R.B., J.F. Mesen, Z. Tchoundjeu, K.A. Longman, J. McP Dick, A. Newton, A. Matin, A. Grace, R.C. Munro, and P.N. Muthoka. 1990. Low-technology techniques for the vegetative propagation of tropical trees. Commonwealth For. Rev. 69:247-257.

Loach, K. 1977. Leaf water potential and the rooting of cuttings under mist and polyethylene. Physiol. Plant. 40:19 1-1 97.

Loach, K. 1988. Water relations and adventitious rooting, p. 102- 116. In: T.D. Davis, B.E. Hassig, and N. Sankhla (eds.) Adventitious root formation in cuttings. Dioscorides Press, Portland, Ore.

Newton, A.C. and A.C. Jones. 1993a. Characterization of microclimate in mist and non-mist propagation systems. J. Hort. Sci. 68:421-430.

Newton, A.C. and A.C. Jones. 1993b. The water status of leafy cuttings of four tropical tree species in mist and non-mist propagation systems. J. Hort. Sci. 68:653-663. 